\title{
Colobronchial fistula: a late complication of appendicitis
}

\author{
S ASHLEY, SARAH K CORLETT, R WINDLE, J B COOKSON \\ From the Departments of General Surgery and Medicine, Glenfield General Hospital, Leicester
}

Colobronchial fistula is a rare occurrence, being found mostly in patients with chronic abdominal sepsis and a subphrenic abscess. We report a case that occurred four years after the abscess.

\section{Case report}

A 73 year old woman presented in 1982 with generalised peritonitis. Laparotomy showed a perforated appendix with free peritoneal pus and appendicectomy was performed with peritoneal lavage. Her postoperative recovery was delayed by wound dehiscence, which required resuture, and by a suspected left subphrenic abscess, which resolved with conservative management. She was discharged home after nine weeks.

Four years later she presented with a six month history of cough, worse at night and productive of copious brown, bitter tasting sputum streaked with blood. She had had night sweats and a poor appetite, and had lost $6 \mathrm{~kg}$ in weight. She had also been passing loose stools, two to three times daily, for three months. She was a lifelong non-smoker.

On examination there were bilateral basal crackles, worse on the left, and there was a large incisional hernia. Investigation showed a haemoglobin concentration of $8.7 \mathrm{~g} / \mathrm{dl}$, with red cell indices suggesting iron deficiency and a plasma viscosity of $2.61 \mathrm{cp}$. A chest radiograph showed some obscurity of the left hemidiaphragm. Pulmonary function tests showed no abnormality. Escherichia coli was grown from the sputum, but this was thought to be related to the several courses of antibiotics that had previously been prescribed. Mild inflammatory changes in the bronchi of the left lower lobe were found on bronchoscopy. A barium swallow showed normal appearances with no evidence of aspiration. A barium enema, performed to investigate the anaemia, showed barium passing via the splenic flexure into the bronchi of the left lower lobe (figure). A diagnosis of colobronchial fistula was made as a consequence of her previous abdominal sepsis and suspected subphrenic abscess.

Surgery was performed after standard preparation of the bowel, the patient being ventilated with a double lumen endobronchial tube. With the patient tilted to the right the left upper quadrant was explored via an upper midline incision and the colon was followed to adhesions surrounding an abscess cavity between the splenic flexure, diaphragm, and spleen. The cavity was opened, revealing $10 \mathrm{ml}$ of pus, the colon was mobilised, and the affected segment resected

Address for reprint requests: Mr Simon Ashley, Cardiovascular Research Unit, Killingbeck Hospital, Leeds LS14 6UH.

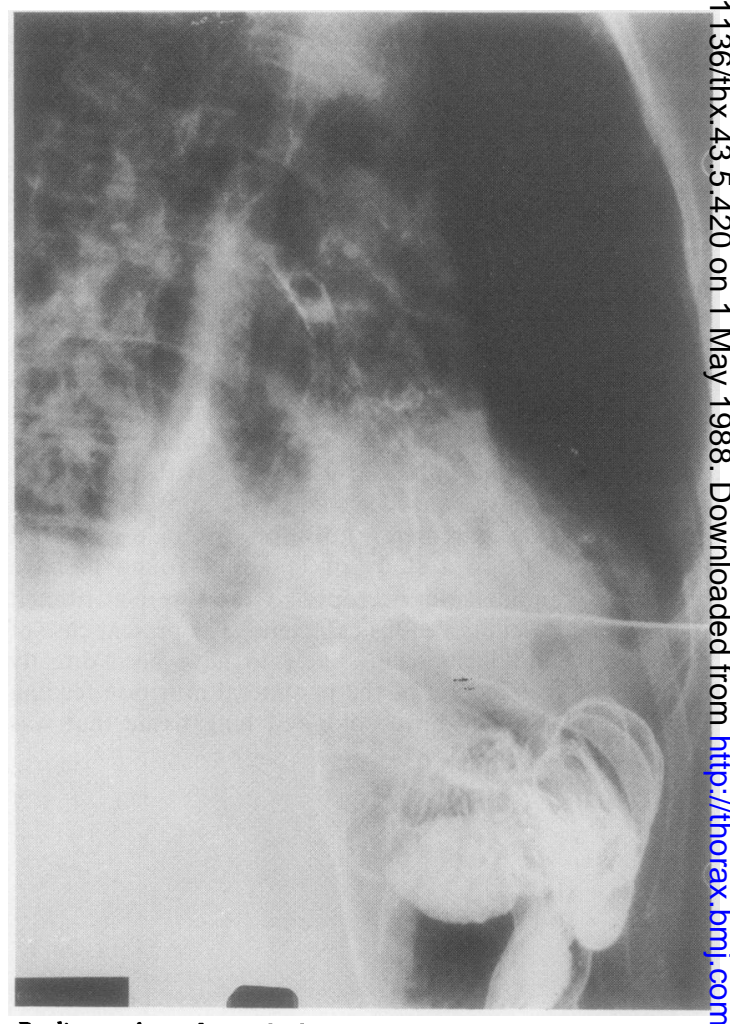

Radiograph performed after a barium enema, showing that barium has passed via the splenic flexure into the bronchi of the left lower lobe.

with a primary anastomosis. An air leak through the diaphragm was detected by overinflating the left lung. A drain was inserted down to the left subphrenic space and the incisional hernia was repaired. The patient made an uneventeo ful recovery and has remained well subsequently.

\section{Discussion}

Colobronchial fistula is very rare. It usually occurs as a resuli্D of spontaneous rupture of a subphrenic abscess into adjacen colon and through the diaphragm into the pleural cavity, and then into the overlying adherent lung. In a reported series of 3608 cases of subphrenic abscess ${ }^{1}$ the incidence of ruptures 
into the lung was $10 \cdot 5 \%$. This review was, however, conducted before the antibiotic era, and it fails to mention colobronchial fistula as a further complication. Reports cite colitis, ${ }^{23}$ pyonephrosis, ${ }^{4}$ tuberculosis, ${ }^{5}$ and carcinoma of the colon ${ }^{67}$ as circumstances in which colobronchial fistula has occurred. In most cases of colobronchial fistula there is a long history of chronic abdominal sepsis with a proved or suspected subphrenic abscess. The diagnosis may be suspected in a patient with such a history who presents with symptoms and signs of lung suppuration, particularly if copious brown sputum is produced that grows Gram negative organisms. The diagnosis is usually, but not always, confirmed by barium enema, although this may be dangerous: in two patients rapid deterioration followed reflux of faecal matter into the lungs, ${ }^{38}$ and this may have contributed to the deaths of two others. ${ }^{78}$ Bronchography might be considered as an alternative diagnostic procedure.

The treatment is surgical, as outlined above, but faecal diversion and lobectomy may be required.

\section{References}

1 Ochsner A, DeBakey ME. Subphrenic abscess: collective review and analysis of 3608 collected and personal cases. Surg Gynecol Obstet 1938;66:426-38.

2 Aufses AH, Kark AE. Bronchial fistula complicating subphrenic abscess. Mt Sinai J Med NY 1973;40:758-61.

3 Swerdlow B, Jenkins JG. Anaesthesia for colobronchial fistula. Anaesthesia 1985;40:42-4.

4 Caberwal D, Katz J, Reid R, et al. A case of nephrobronchial and colobronchial fistula presenting as lung abscess. J Urol 1977;117:371-3.

5 Crotis TJ, Dalrymple JD, Buhrumann JR. Tuberculous bronchocolic fistula. S Afr Med J 1978;54:795-6.

6 Savage PJ, Donovan WM, Kilgore TL. Colobronchial fistula in a patient with carcinoma of the colon. Southern Med J 1982;75:246-7.

7 Hines DR, Granson PA, Taylor RL. Colo-pleuro-bronchial fistula due to carcinoma of the colon. Ann Thorac Surg 1966;2:594-6.

8 Carmichael JHE, Franklin PP. Broncho-pleuro-colonic fistula. $\mathrm{Br}$ $J$ Radiol 1963;36:528-30. 